\title{
Comparison of efficacy and safety between oral and intravenous administration of tranexamic acid for primary total knee/hip replacement: a meta-analysis of randomized controlled trial
}

\author{
Wei Ye ${ }^{1 *}$, Yafang Liư ${ }^{2}$, Wei Feng Liư ${ }^{1}$ Xiao Long Li ${ }^{1}$, Yanqiang Fei ${ }^{1}$ and Xing Gao ${ }^{1}$
}

\begin{abstract}
Background: Tranexamic acid (TXA) has been demonstrated to reduce blood loss following primary total knee and hip arthroplasty. This study aimed to compare the efficacy and safety of oral and intravenous tranexamic acid for primary total knee and hip arthroplasty.

Methods: The PubMed, Embase, and Cochrane Library databases were searched for relevant studies published before June 20, 2019. Studies clearly reporting a comparison of oral and intravenous TXA were selected, and total blood loss (TBL), the decline in hemoglobin (DHB), deep vein thrombosis (DVT), intramuscular venous thrombosis (IVT), the length of hospital stay, and the transfusion rate were evaluated. The weighted mean differences and relative risks were calculated using a fixed-effects or random-effects model.

Results: Ten studies involving 1140 (oral 557; intravenous 583) patients were included in this meta-analysis. There was no significant difference in terms of total blood loss, the decline in hemoglobin, the length of hospital stay, the incidence of DVT or IVT, or the transfusion rate between the oral and intravenous groups, and five studies reported that oral TXA was associated with a lower cost.
\end{abstract}

Conclusion: Our research suggests that compared with intravenous use of TXA, the oral approach has similar clinical outcomes and is less expensive for total joint replacement patients.

Keywords: Oral, Intravenous, Tranexamic acid, Total knee/hip arthroplasty

\section{Introduction}

Total knee/hip arthroplasty (TKA/THA) is a reliable surgical procedure for patients suffering from moderate to severe degenerative knee or hip joint diseases and osteoarthritis pain, but perioperative bleeding is a major challenge for surgeons. Previous studies have reported that the estimated blood loss was between 800 and $1800 \mathrm{ml}[1,2]$. To overcome this problem, various methods are available to reduce perioperative blood loss, such as blood

\footnotetext{
* Correspondence: ye_wei8912@163.com

${ }^{1}$ Department of Orthopedics Medicine, Wujin People's Hospital, YongNing North Road No. 2, Changzhou 213000, Jiangsu Province, China

Full list of author information is available at the end of the article
}

transfusions, tourniquet use, iron supplements, and the administration of anti-fibrinolytic drugs [3-6]. As we all know, transfusions extend not only the patient's rehabilitation time but also the length of hospital stay. They incur a considerable cost and are also associated with the risk of transfusion reactions, infectious diseases, and inhibition of the immune system [7-9]. Tranexamic acid (TXA) is a synthetic agent that exerts its anti-fibrinolytic effects by inhibiting plasminogen. TXA inhibits plasminogen activation by binding plasmin to fibrin, which leads to clot stabilization and reduces blood loss. TXA is a simple, cheap, and effective drug for reducing perioperative blood loss in total knee 


\section{श्राड MN \\ PRISM M \\ PRISMA 2009 Flow Diagram}

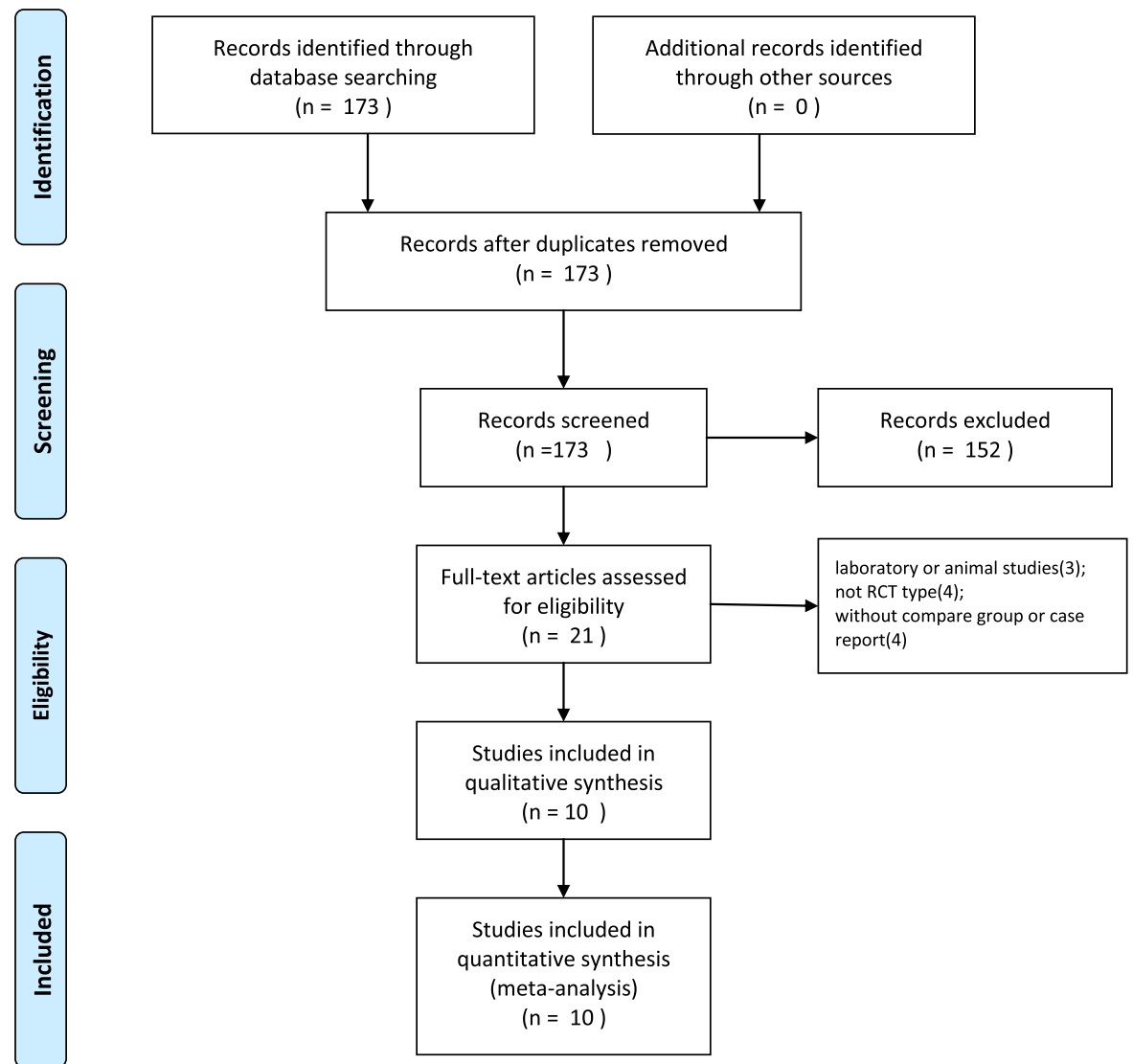

Fig. 1 Search strategy flow diagram

arthroplasty regardless of whether it is applied directly to the surgery site or through intravenous administration, which has been reported in previous publications [10-14]. However, there is still no consensus about which route is the best method application of TXA for total joint replacement patients. This study aimed to compare the efficacy and safety of oral and intravenous tranexamic acid for primary total knee and hip arthroplasty patients.

\section{Materials and methods}

\section{Search strategy}

PubMed, Cochrane Library, and Embase databases were searched independently by two investigators to retrieve relevant studies published before June 20, 2019. The search criteria "tranexamic acid," "TXA," "total knee/hip arthroplasty," "TKA/THA," "total joint replacement," “TKR/THR," "oral," and "intravenous" were used in key words for search. All studies selected were reviewed independently by the authors and examined for broadening the potential studies through the "related articles" function. Thus, the reference lists of the included articles were also manually checked to find relevant studies that were not found during the database searches.

Inclusion criteria are the following: (1) adult patients with knee or hip joint degenerative disease and received primary TKA/THA; (2) includes TXA oral and intravenous application groups; (3) examination includes any one among total blood loss, decline of hemoglobin (DHB), DVT, IVT, length of hospital stay, and transfusion rate. Exclusion criteria are the following: (1) Joint replacement is not for joint degenerative disease such as trauma, tumors, or bilateral joint replacement; (2) Study only report oral or intravenous group or case report; (3) Animal or laboratory study. 
Table 1 The information of included studies

\begin{tabular}{|c|c|c|c|c|c|c|c|}
\hline Study & Country & Hip/knee & Oral & IV & TXA administration & TXA cost & Outcomes \\
\hline Yuan 2017 [15] & China & K & 140 & 140 & $\begin{array}{l}\text { O: } 20 \mathrm{mg} / \mathrm{kg}^{*} 2 \text { dose } \\
\text { IV: } 20 \mathrm{mg} / \mathrm{kg}^{*} 2 \text { dose }\end{array}$ & $\begin{array}{l}\text { O: } \$ 274.81 \\
\text { IV: } \$ 860.28\end{array}$ & $\mathrm{IVT}$, DVT, DHB, transfusion rate \\
\hline Luo 2018 [16] & China & $\mathrm{H}$ & 60 & 60 & $\begin{array}{l}\text { O: } 2 \mathrm{~g}^{*} 1 \mathrm{dose} \\
\text { IV: } 20 \mathrm{mg} / \mathrm{kg}^{*} 1 \text { dose }\end{array}$ & $\begin{array}{l}\text { O: } \$ 68.11 \\
\text { IV: } \$ 472.44\end{array}$ & $\mathrm{TBL}, \mathrm{DHB}$, transfusion rate \\
\hline Wang 2018 [17] & China & K & 60 & 60 & $\begin{array}{l}\text { O: } 2 \mathrm{~g}^{*} 1 \mathrm{dose} \\
\text { IV: } 20 \mathrm{mg} / \mathrm{kg}^{*} 1 \text { dose }\end{array}$ & $\begin{array}{l}\text { O: } \$ 68.11 \\
\text { IV: } \$ 474.1\end{array}$ & TBL, DHB, DVT, transfusion rate \\
\hline Fillingham 2016 [18] & USA & K & 34 & 37 & $\begin{array}{l}\text { O: } 1950 \mathrm{mg}^{*} 1 \text { dose } \\
\text { IV: } 1 \mathrm{~g}^{* 1} \text { dose }\end{array}$ & NR & $\mathrm{TBL}, \mathrm{DHB}, \mathrm{HS}$, transfusion rate \\
\hline Wu 2018 [19] & China & $\mathrm{H}$ & 50 & 50 & $\begin{array}{l}\text { O: } 1 \mathrm{~g}^{* 1} \text { dose } \\
\text { IV: } 1 \mathrm{~g}^{* 3} \text { dose }\end{array}$ & $\begin{array}{l}\text { O: } \$ 85.14 \\
\text { IV: } \$ 447\end{array}$ & $\mathrm{TBL}, \mathrm{DHB}, \mathrm{IVT}, \mathrm{HS}$, transfusion rate \\
\hline Cao-K 2018 [20] & China & K & 59 & 59 & $\begin{array}{l}\mathrm{O}: 500 \mathrm{mg} 4 \text { dose } \\
\mathrm{IV}: 20 \mathrm{mg} / \mathrm{kg}^{*} 1 \text { dose } \\
\text { and } 1 \mathrm{~g}^{*} 3 \text { dose }\end{array}$ & NR & TBL, DVT, HS \\
\hline Zhao 2018 [21] & China & $\mathrm{H}$ & 40 & 40 & $\begin{array}{l}\text { O: } 20 \mathrm{mg} / \mathrm{kg}^{*} 2 \text { dose } \\
\text { IV: } 15 \mathrm{mg} / \mathrm{kg}^{*} 2 \text { dose }\end{array}$ & $\begin{array}{l}\text { O: } \$ 77.48 \\
\text { IV: } \$ 648.96\end{array}$ & $\mathrm{TBL}, \mathrm{DHB}, \mathrm{IVT}$, transfusion rate \\
\hline Kayupov 2017 [22] & USA & $\mathrm{H}$ & 40 & 43 & $\begin{array}{l}\text { O: } 1950 \mathrm{mg}^{*} 1 \text { dose } \\
\text { IV: } 1 \mathrm{~g}^{* 1} \text { dose }\end{array}$ & NR & $\mathrm{TBL}, \mathrm{DHB}, \mathrm{HS}$, transfusion rate \\
\hline Cao-H 2018 [23] & China & $\mathrm{H}$ & 54 & 54 & $\begin{array}{l}\text { O: } 500 \mathrm{mg}^{*} 4 \text { dose } \\
\text { IV: } 20 \mathrm{mg} / \mathrm{kg}^{*} 1 \text { dose }\end{array}$ & NR & IVT, DVT \\
\hline Zohar-L 2004 [24] & Israel & K & 20 & 20 & $\begin{array}{l}\text { O: } 1 \mathrm{~g}^{*} 3 \text { dose } \\
\text { IV: } 15 \mathrm{mg} / \mathrm{kg}^{*} 1 \text { dose and } 10 \mathrm{mg} / \mathrm{kg}^{*} 1 \text { dose }\end{array}$ & $N R$ & HS, transfusion rate \\
\hline Zohar-S 2004 [24] & Israel & K & 20 & 20 & $\begin{array}{l}\text { O: } 1 \mathrm{~g}^{*} 3 \text { dose } \\
\text { IV: } 15 \mathrm{mg} / \mathrm{kg}^{*} 1 \text { dose and } 10 \mathrm{mg} / \mathrm{kg}^{*} 1 \text { dose }\end{array}$ & $N R$ & HS, transfusion rate \\
\hline
\end{tabular}

DVT deep vein thrombosis, IVT intramuscular venous thrombosis, DHB decline of hemoglobin, TBL total blood loss, HS length of hospital stay

\section{Data extraction}

Each article's variables and outcomes of interest and assessment of the methodological quality were reviewed independently by two readers. If there was a difference of opinion, the problems were resolved through discussion and consensus. The methodological quality of the trials was assessed through the Cochrane Handbook for Systematic Reviews of Interventions 5.1 .

\section{Statistical analysis}

The statistical analysis was performed using Review Manager 5.1 for Windows System (Cochrane Collaboration, Nordic Cochrane Centre, Copenhagen, Denmark). Categorical dichotomous variables were analyzed with relative risks (RRs), continuous variables were assessed with the weighted mean difference, and $P<0.05$ was considered statically significant; the $95 \%$ confidence intervals (CIs) were reported. Heterogeneity was considered significant if the $P$ value was less than 0.1 . The value of $I^{2}$ statistics was used to assess the degree of heterogeneity $\left(I^{2}<25 \%\right.$, no heterogeneity; $I^{2}=25-50 \%$, moderate heterogeneity; $I^{2}>50 \%$, large or extreme heterogeneity); if $I^{2}>50 \%$, a fixed-effects model was used. The presence of publication bias was assessed by a visual inspection of a funnel plot and the Begg and Egger tests (with $P<0.05 \quad$ considered statistically significant).

\section{Results}

Literature search

The initial literature search retrieved 173 relevant articles (duplicates were discarded). After a careful screening of the titles, 152 articles were excluded for not investigating the topic of interest. After reviewing the abstracts, 11 articles were excluded (3 laboratory or animal studies, 4 not RCT type, 4 without compare group or case report). Therefore, leaving 10 studies matched the selection criteria and were suitable for meta-analysis (Fig. 1). A total of 1140 (oral 557; intravenous 583) patients were enrolled in the studies; the information of the included studies is summarized in Table 1 [15-24]. They are all RCT studies and the methodological bias of this study was low (Fig. 2).

\section{Main analysis}

Ten studies involving 1140 patients were included in this meta-analysis; compared with intravenous administration of TXA, oral TXA have similar outcomes in the total blood loss (TBL) $[\mathrm{MD}=-3.67$, 95\% CI $(-45.12$ to 37.78), $P=0.86]$, decline of hemoglobin $(\mathrm{DHB})[\mathrm{MD}=-0.03,95 \% \mathrm{CI}(-0.11$ to 


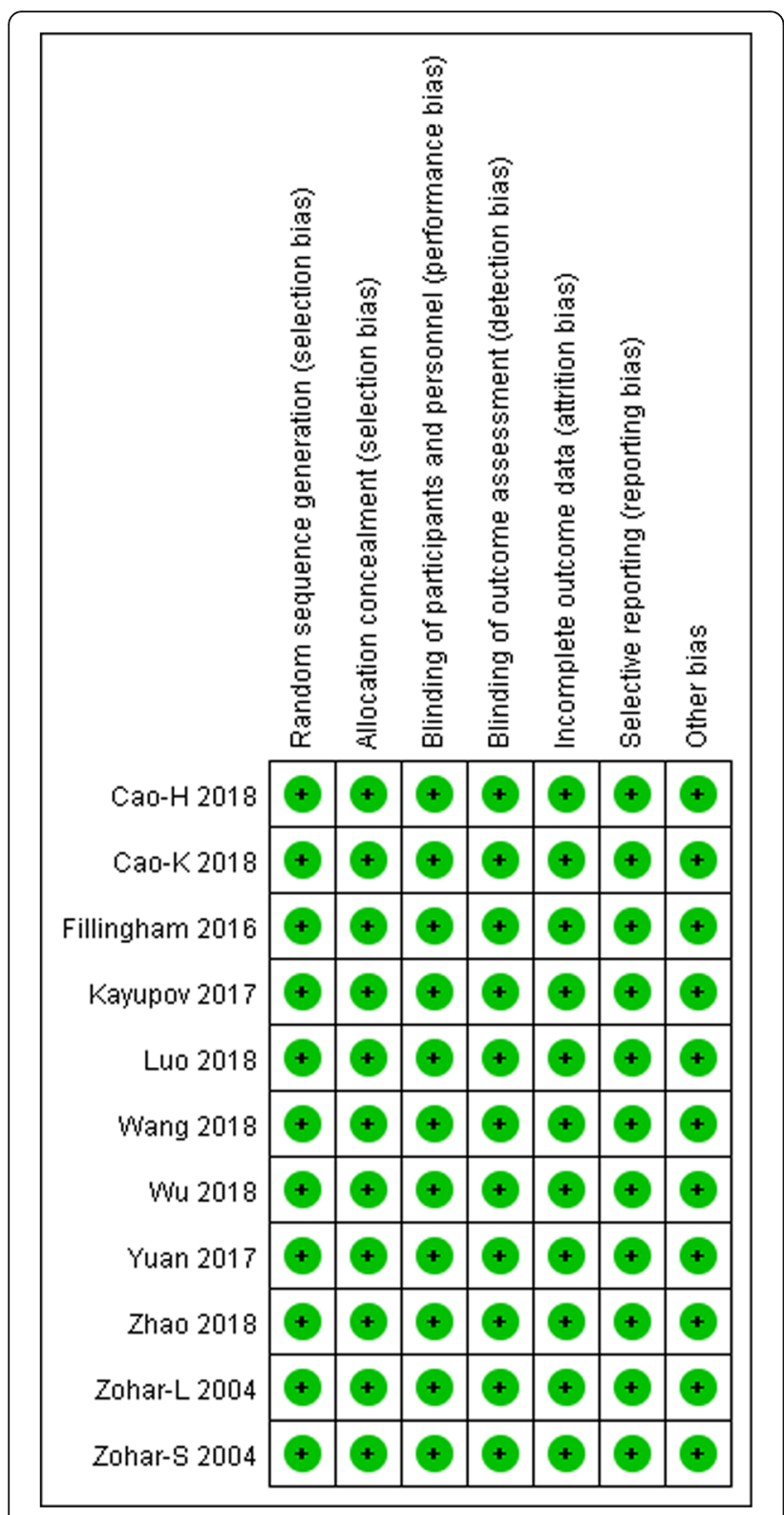

Fig. 2 Summary of the methodological quality of the selected studies
$0.05), P=0.45]$, length of hospital stay (HS) $[\mathrm{MD}=$ $0.09,95 \% \mathrm{CI}(-0.10$ to 0.27$), P=0.36$ ] and there have no significant difference in terms of DVT $[\mathrm{OR}=0.37,95 \% \mathrm{CI}(0.10$ to 1.40$), P=0.14]$, IVT $[\mathrm{OR}=0.71,95 \% \mathrm{CI}(0.36$ to 1.38$), P=0.31]$, and transfusion rate $[\mathrm{OR}=1.03,95 \% \mathrm{CI}(0.65$ to 1.61$)$, $P=0.91$, but five studies suggested that oral TXA significantly reduced TXA cost compared with intravenous application (Figs. 3, 4, 5, 6, 7, 8, 9, 10, $11,12,13$, and 14).

\section{Discussion}

For TXA, our findings showed that compared with intravenous administration, oral application resulted in a lower TXA cost for total joint replacement patients. However, there were similar outcomes in terms of total blood loss (TBL), the decline in hemoglobin (DHB), and the length of hospital stay (HS) between the two treatment groups. In addition, the incidence of DVT and IVT and the transfusion rate between the two treatment groups showed no significant differences. The results suggested that oral TXA application is cheaper than intravenous administration and has the same efficacy and safety. Furthermore, oral TXA is a simpler procedure for reduced blood loss. Thus, we considered oral TXA to be more accepted for total joint replacement patients.

Blood loss is a common complication for total knee and hip arthroplasty patients that might result in swelling, stiffness, and delayed rehabilitation. Several techniques have been used for reduced blood loss during surgery, and allogeneic blood transfusions are a popular method for improving patients' postoperative HB levels. Because they inhibit the immune system and increase the chance of infection, various risks of transfusion have been reported in previous studies. Thus, there is an urgent need for a more effective and safer method [25-28]. TXA is an antifibrinolytic drug that has been demonstrated to effectively reduce blood loss in TKA and THA patients in

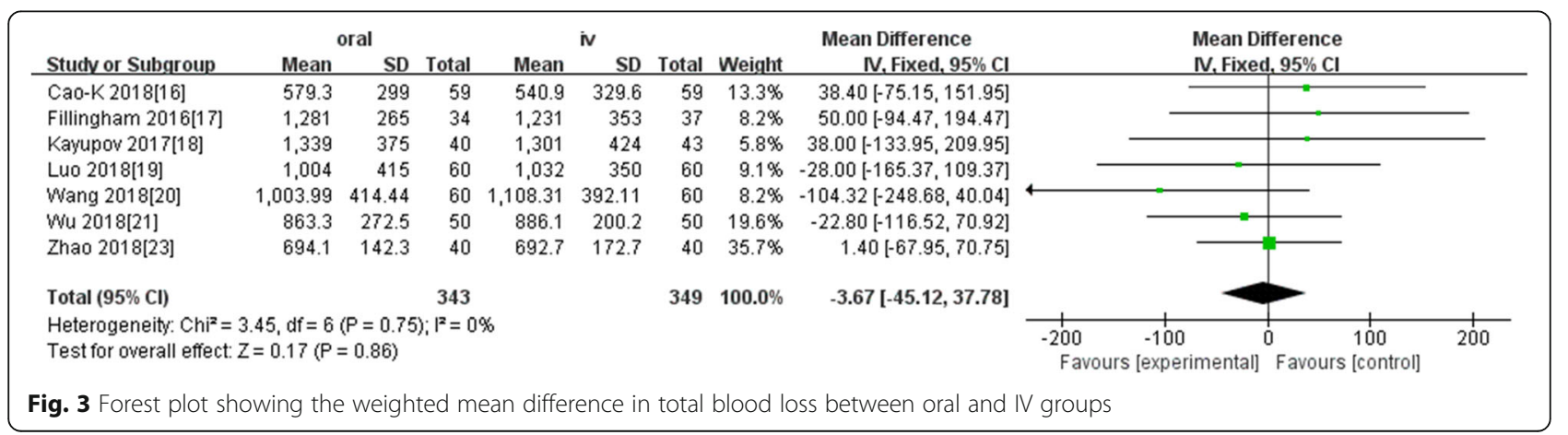




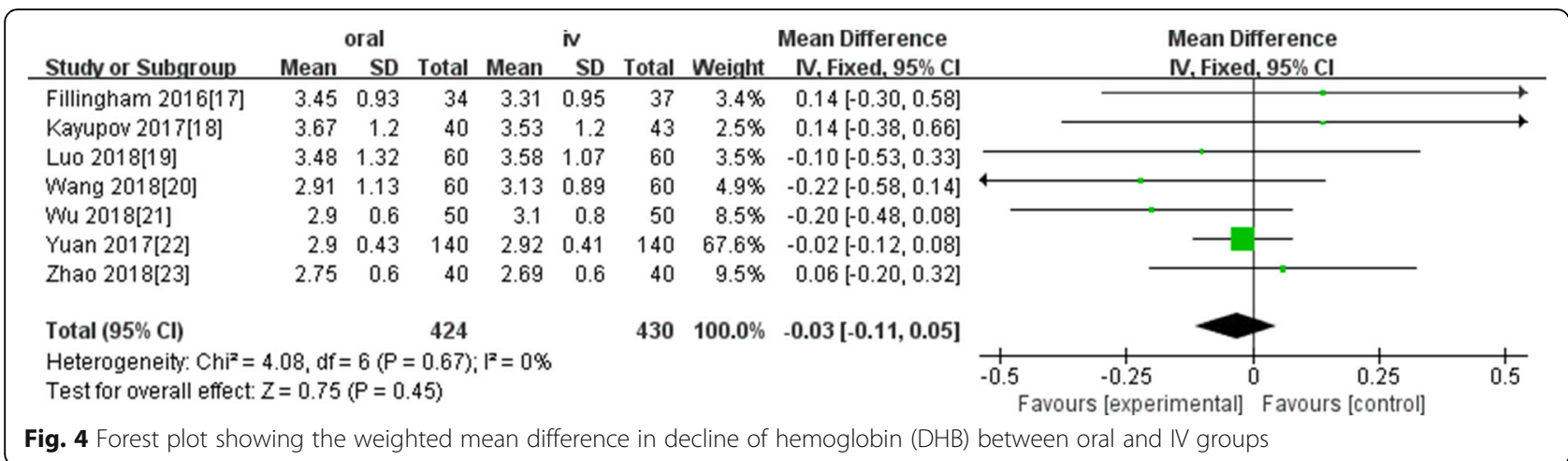

many publications. However, the majority of reports focused on topical and intravenous TXA administration. Previous studies have confirmed that there is similar effectiveness and safety in reducing total blood loss and transfusions between the two treatments, but little is known about the use of oral TXA in primary total joint replacement. Alipour et al. [29] reported that $1 \mathrm{~g}$ oral TXA applied $2 \mathrm{~h}$ preoperation significantly reduced blood loss compared with the placebo group. Lee et al. [30] demonstrated that patients who received oral TXA administration showed less total blood loss than placebo patients. Although Irwin et al. [31] reported that the oral TXA group ( $2.5 \mathrm{~g} /$ $\mathrm{dL}$ ) had a greater change in decline in $\mathrm{Hb}$ than the IV TXA group $(2.3 \mathrm{~g} / \mathrm{dL})$, the credibility of the results posed a challenge due to the retrospective design. Thus, to ensure the accuracy of the results, only RCTs were included in this research, and our results suggested that oral TXA was equally effective in terms of total blood loss and decline in HB compared with IV TXA. Additionally, five studies [15-17, 19, 21] have confirmed the cost-effective benefits of oral TXA (O: $\$ 68.11 / 68.11 / 85.14 / 274.81 / 77.48 ; \quad I V$ : $\$ 472.44 / 474.1 / 447 / 860.28 / 648.96)$.

Transfusion is also a major problem; more blood loss during TKA or THA often results in transfusion, and Johansson et al. [32] found that intravenous TXA could significantly reduce blood loss and the transfusion cost during total hip arthroplasty compared with the placebo group. Husted et al. [33] performed RCT studies to evaluate the effectiveness of TXA for primary THA patients, and the results showed that intravenous TXA achieved less blood loss and a lower transfusion rate compared with the control group. Performing a retrospective analysis of 1018 patients, Gillette et al. [34] showed that TXA has economic benefits in terms of pharmacy, blood, laboratory, and room and board costs. In addition, previous studies have indicated that oral TXA is also an effective method for preventing blood loss, but there is a limited research focus on comparing the transfusion rate between oral and IV TXA administration. Our findings indicated that oral TXA is equally effective in reducing the transfusion rate compared with IV TXA for primary total joint replacement patients. Furthermore, the length of hospital stay could reflect the progress of patient postoperative recovery and the economic impact. Five studies reported the days of hospital stay, and our results showed that there were no statistically significant differences between the IV and oral TXA groups. Based on the

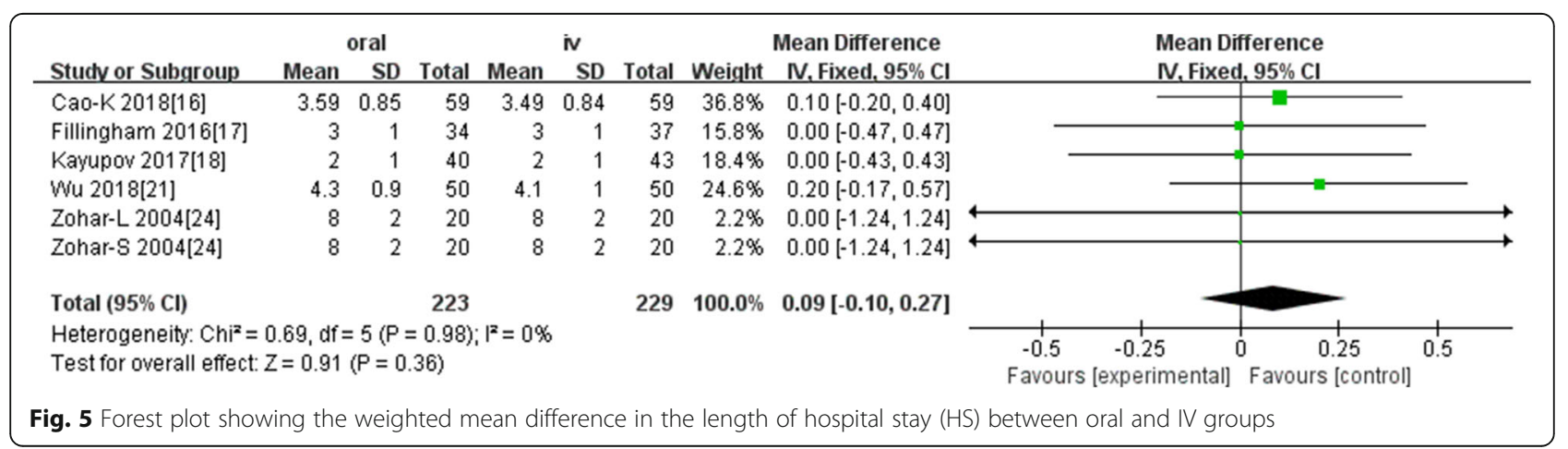




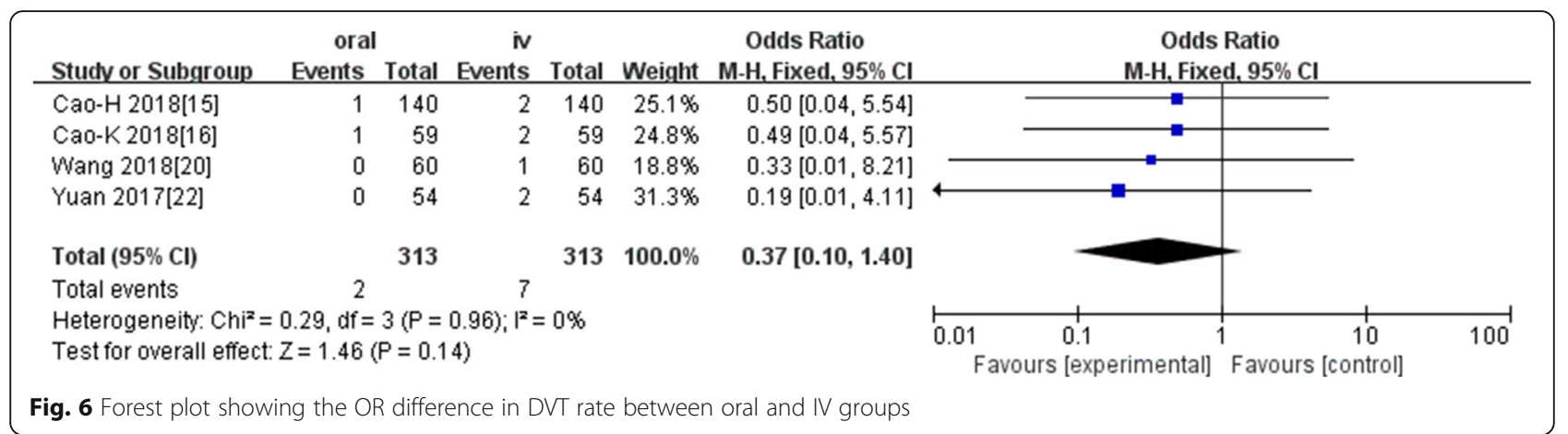

\begin{tabular}{|c|c|c|c|c|c|c|c|c|c|c|c|}
\hline Study or Subgroup & $\begin{array}{c}\text { oral } \\
\text { Events }\end{array}$ & Total & $\begin{array}{r}\text { iv } \\
\text { Events }\end{array}$ & Total & Weight & $\begin{array}{c}\text { Odds Ratio } \\
\text { M-H, Fixed, } 95 \% \mathrm{Cl}\end{array}$ & \multicolumn{5}{|c|}{$\begin{array}{c}\text { Odds Ratio } \\
\text { M-H, Fixed, } 95 \% \mathrm{Cl}\end{array}$} \\
\hline Cao-H 2018[15] & 4 & 54 & 6 & 54 & $26.9 \%$ & $0.64[0.17,2.41]$ & & & $\longrightarrow$ & & \\
\hline Wu 2018[21] & 3 & 50 & 5 & 50 & $22.8 \%$ & $0.57[0.13,2.55]$ & & & & & \\
\hline Yuan $2017[22]$ & 6 & 140 & 7 & 140 & $32.4 \%$ & $0.85[0.28,2.60]$ & & & - & & \\
\hline Zhao 2018[23] & 3 & 40 & 4 & 40 & $17.9 \%$ & $0.73[0.15,3.49]$ & & & & & \\
\hline Total $(95 \% \mathrm{Cl})$ & & 284 & & 284 & $100.0 \%$ & $0.71[0.36,1.38]$ & & & & & \\
\hline Total events & 16 & & 22 & & & & & & & & \\
\hline $\begin{array}{l}\text { Heterogeneity: } \mathrm{Chi}^{2}= \\
\text { Test for overall effect }\end{array}$ & $\begin{array}{l}0.20, d f= \\
Z=1.01\end{array}$ & $\begin{array}{l}3(P= \\
(P=0.3\end{array}$ & $\begin{array}{l}0.98) ; 1^{2}= \\
31)\end{array}$ & $=0 \%$ & & & 0.01 & $\begin{array}{l}0.1 \\
\text { s } \exp \end{array}$ & ${ }_{\text {gerimental] }}^{1}$ & $\begin{array}{cc}1 & 10 \\
\text { Favours [control] }\end{array}$ & 100 \\
\hline
\end{tabular}

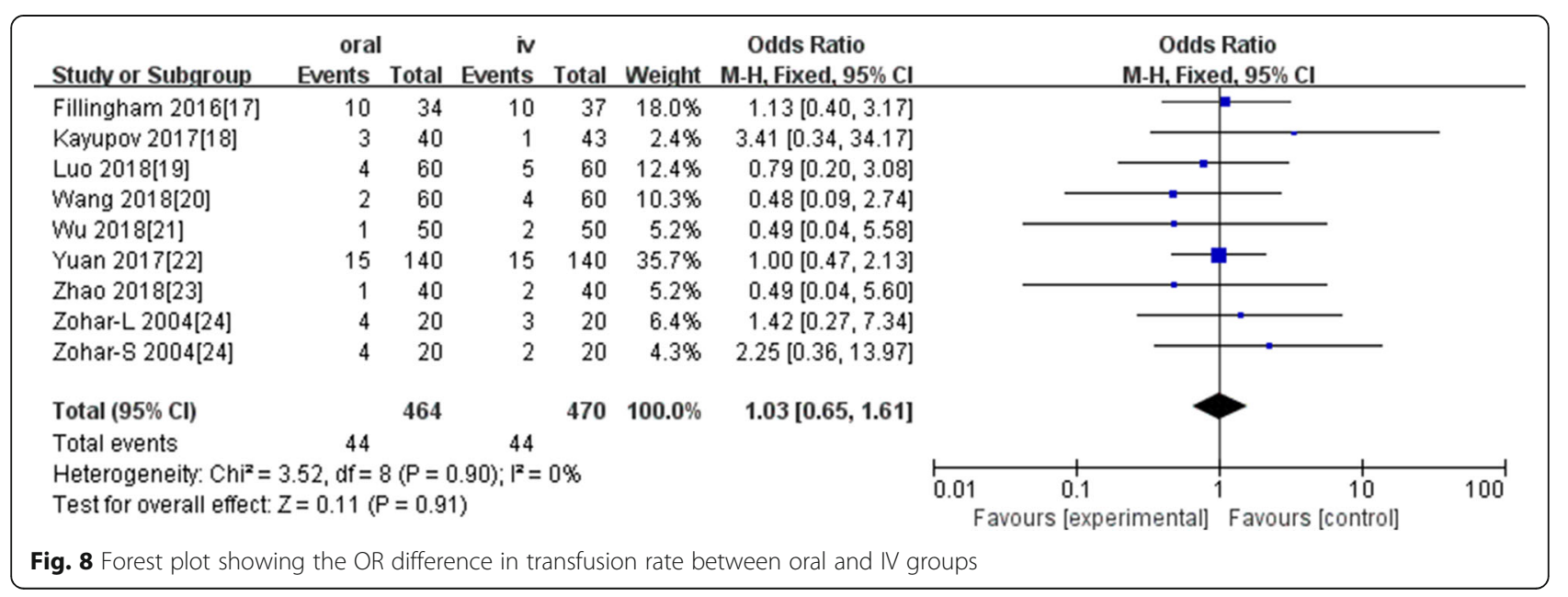




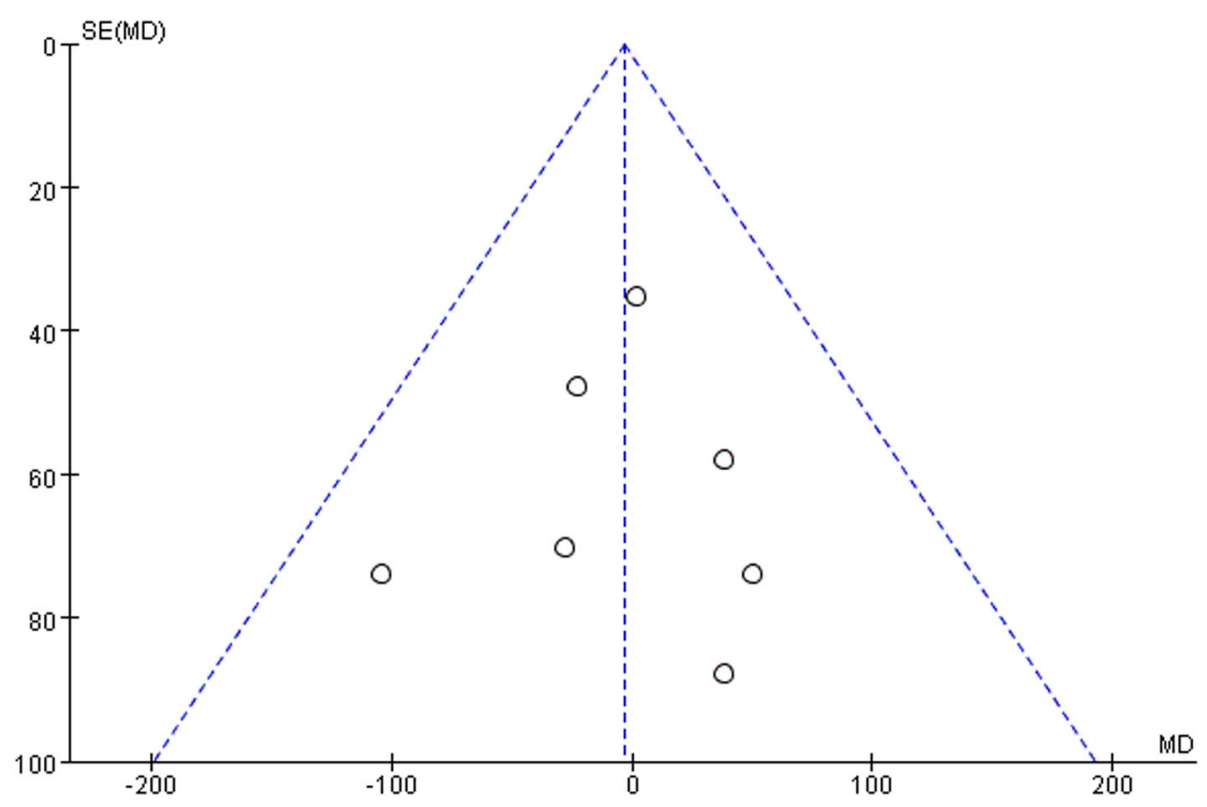

Fig. 9 TBL funnel plot

above results, we believe oral TXA has similar safety and effective outcomes in total joint replacement patients compared with IV TXA administration.

To the best of our knowledge, there is still no consensus regarding the optimal timing and dosing of IV and oral TXA. In our research, the included studies have shown different standard administrations of IV and oral TXA. Five studies recommended only one dose of IV or oral TXA preoperation, while five other studies adopted multiple doses of TXA administered at different time points between pre- and postoperation. The repeated administrations included two, three, and four times. In addition, there was no standard dose in TXA application. The included studies showed that the total oral TXA dose was 1950 $\mathrm{mg}, 2 \mathrm{~g}$, or $3 \mathrm{~g}$ and that the single dose was $10 \mathrm{mg} / \mathrm{kg}$, $15 \mathrm{mg} / \mathrm{kg}$, or $20 \mathrm{mg} / \mathrm{kg}$ in IV TXA groups. Because of the different TXA timing and dosing standards applied in the included studies, we believe that it is difficult to determine the best procedure based on

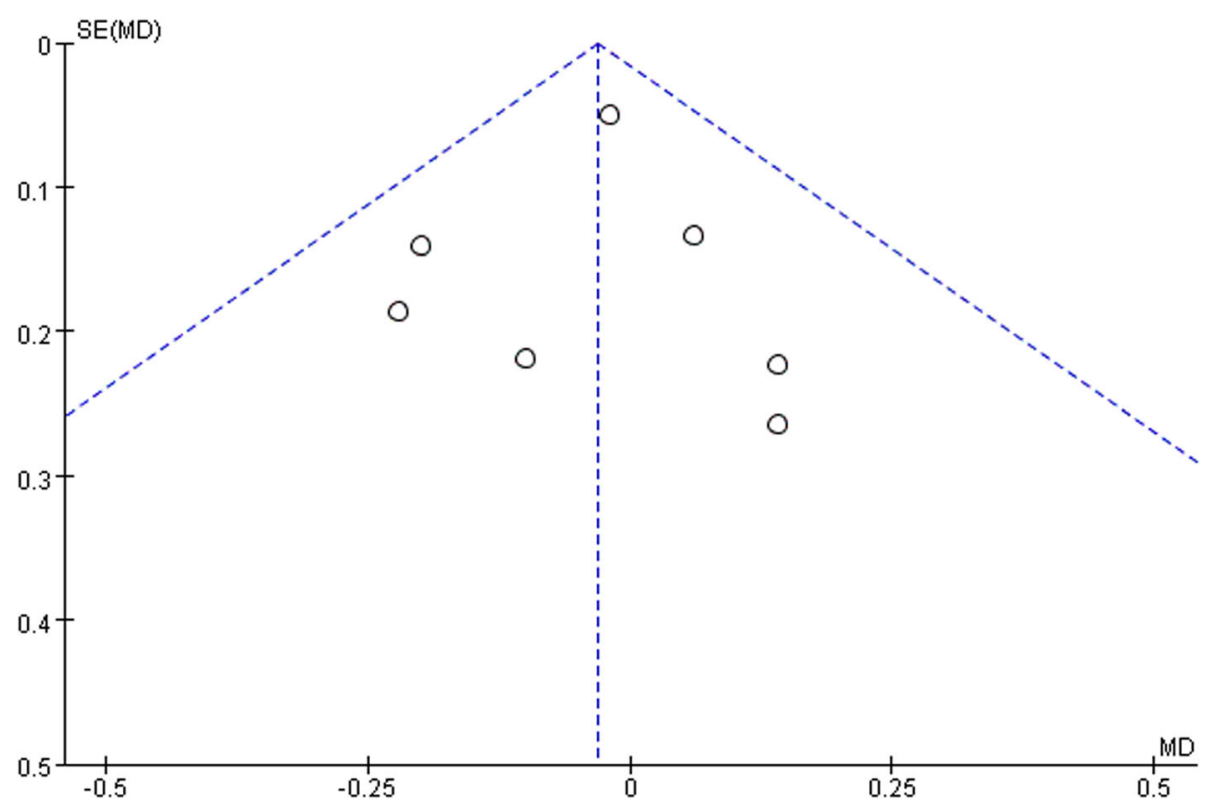

Fig. $10 \mathrm{DHB}$ funnel plot 


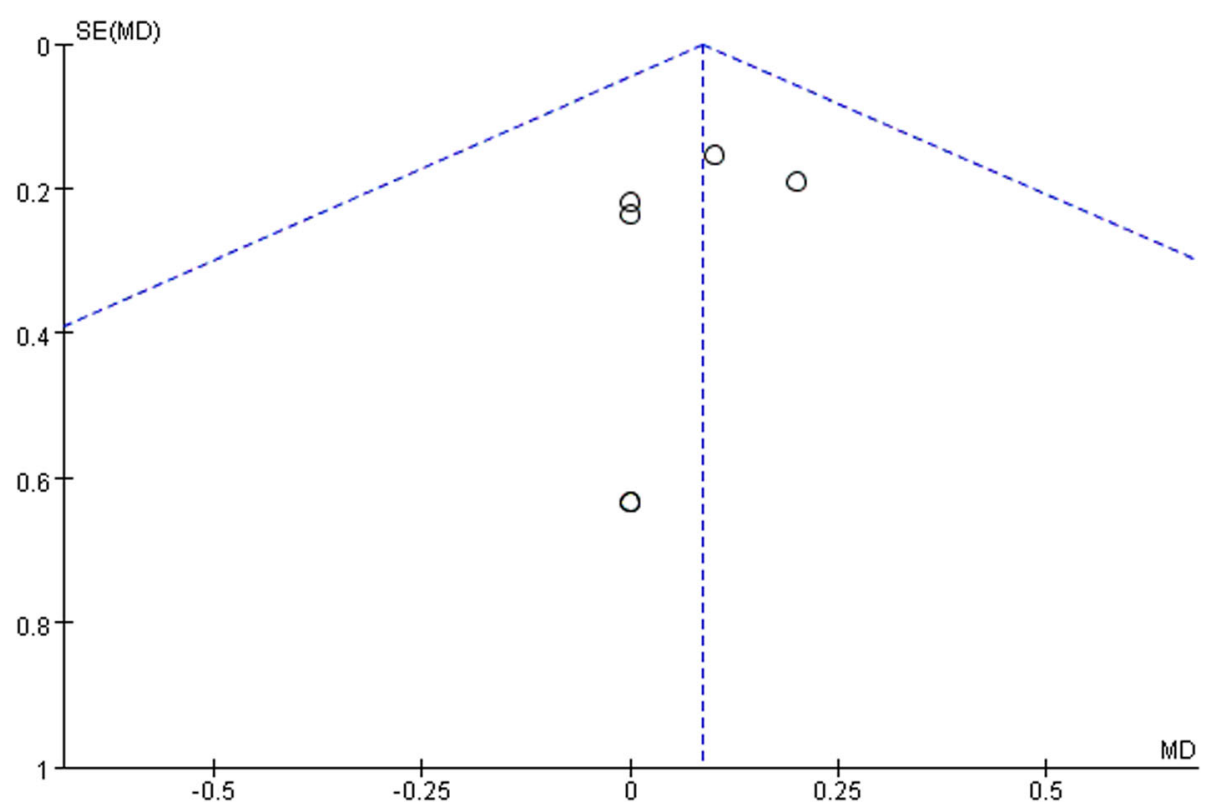

Fig. 11 HS funnel plot

current data, but through our gross analysis, the results demonstrated that a total of $2 \mathrm{~g}$ oral TXA was an effective way of reducing blood loss during total joint replacement regardless of whether single or multiple dose administration is carried out. Although some researchers considered that multiple- or highdose TXA administration can prevent drug concentration and show better outcomes, there is a need for high-quality RCT studies in the future to support this view $[35,36]$.
Many high-quality RCTs have demonstrated safety and efficacy based on different routes of TXA administration compared to placebo groups during TKA or THA, but various complications were also concerns for surgeons, especially the incidence of deep vein thrombosis (DVT) and intramuscular venous thrombosis (IVT). In addition, intravenous TXA could be associated with cardiovascular disease or renal dysfunction [37]. However, our results demonstrated that there were no significant

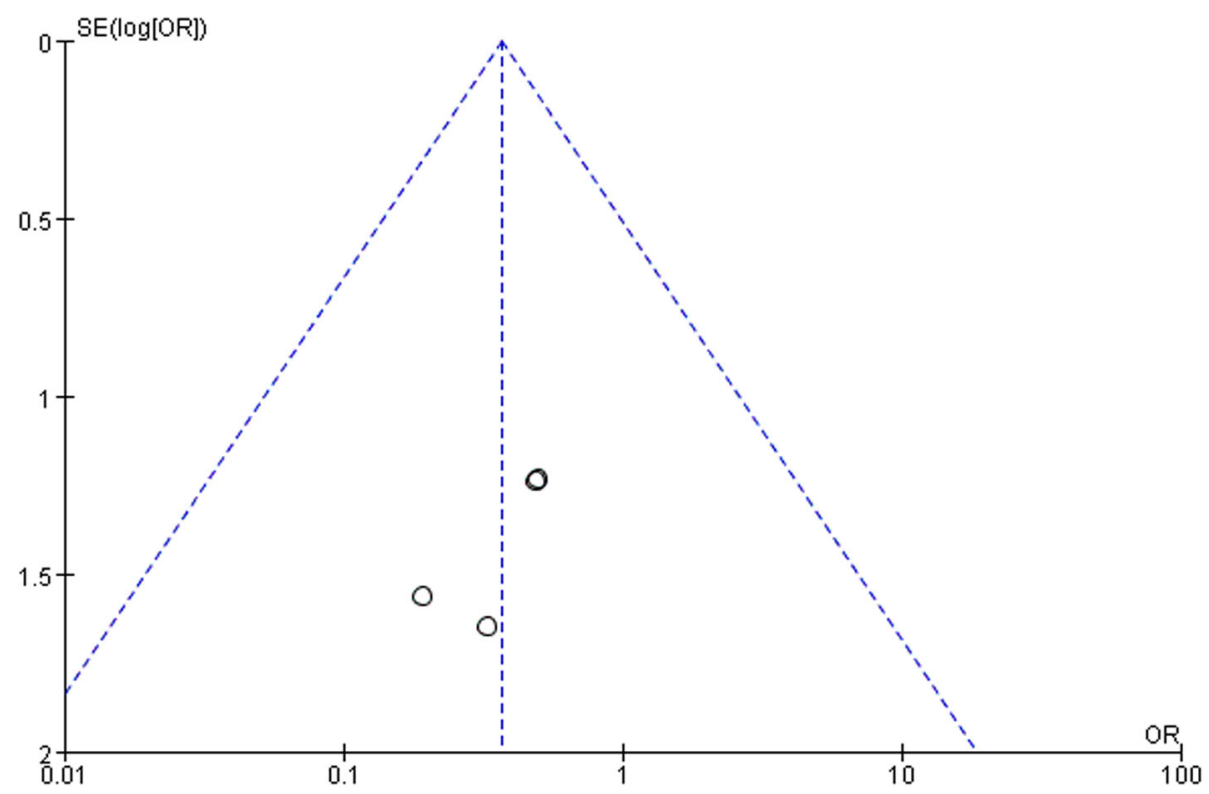

Fig. 12 DVT funnel plot 


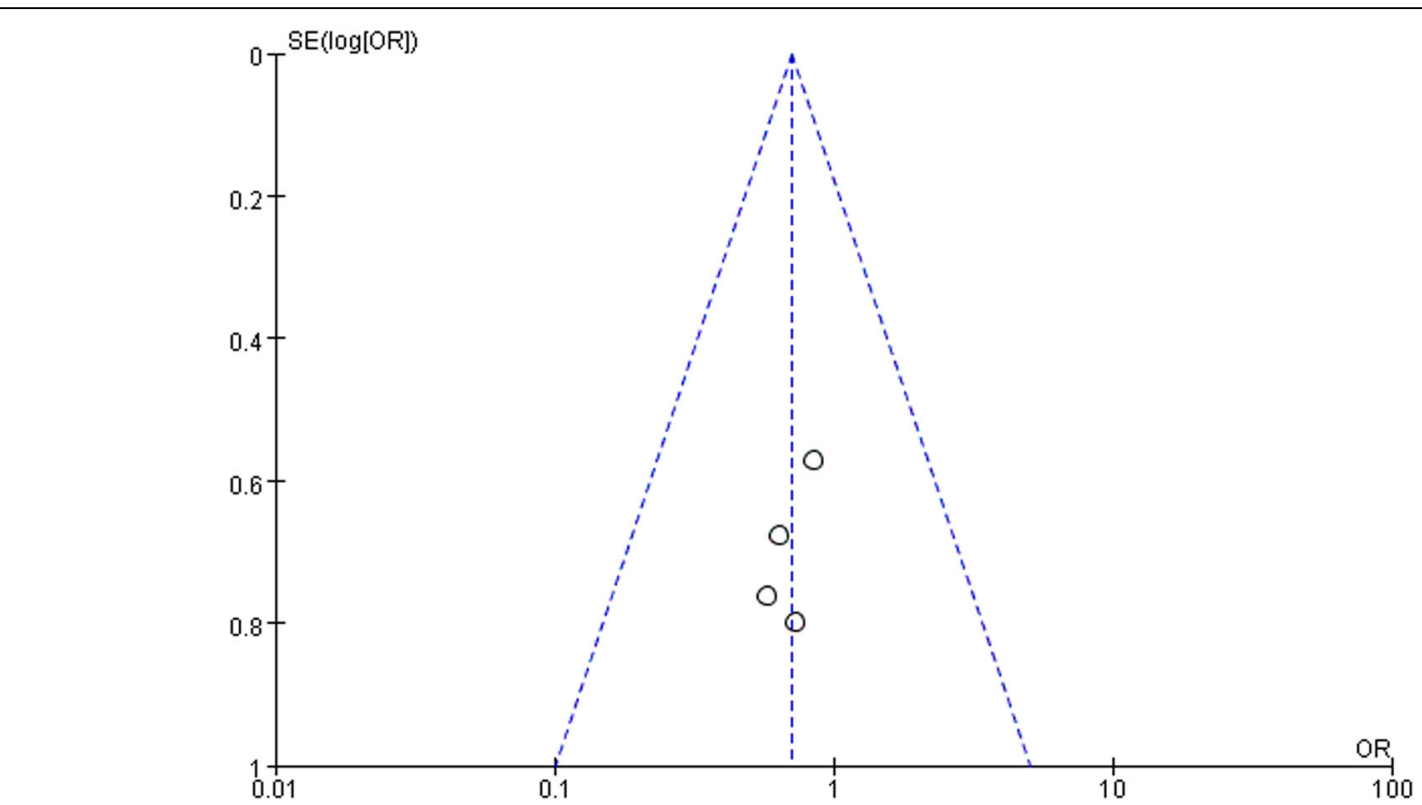

Fig. 13 IVT funnel plot

differences in terms of the incidence of DVT and IVT between the IV and oral TXA treatments. Thus, we believe that oral TXA did not increase the risk of DVT and IVT occurrence compared with IV administration.

However, this meta-analysis has some limitations. First, this meta-analysis included ten studies; the surgeons came from different countries, and the surgical procedures and experiences were different, which may have caused bias in the results. Second, the estimated total blood loss and transfusion depended on different rules, which may have affected the accuracy of the final results. Third, all included studies lacked long-term follow-up, which might have decreased the reliability of the results. Although this meta-analysis contains several limitations, all the included studies have an RCT design, which means that they are still powerful enough to guide future clinical work. Multicenter, prospective, randomized control trials with large sample sizes are needed in the future.

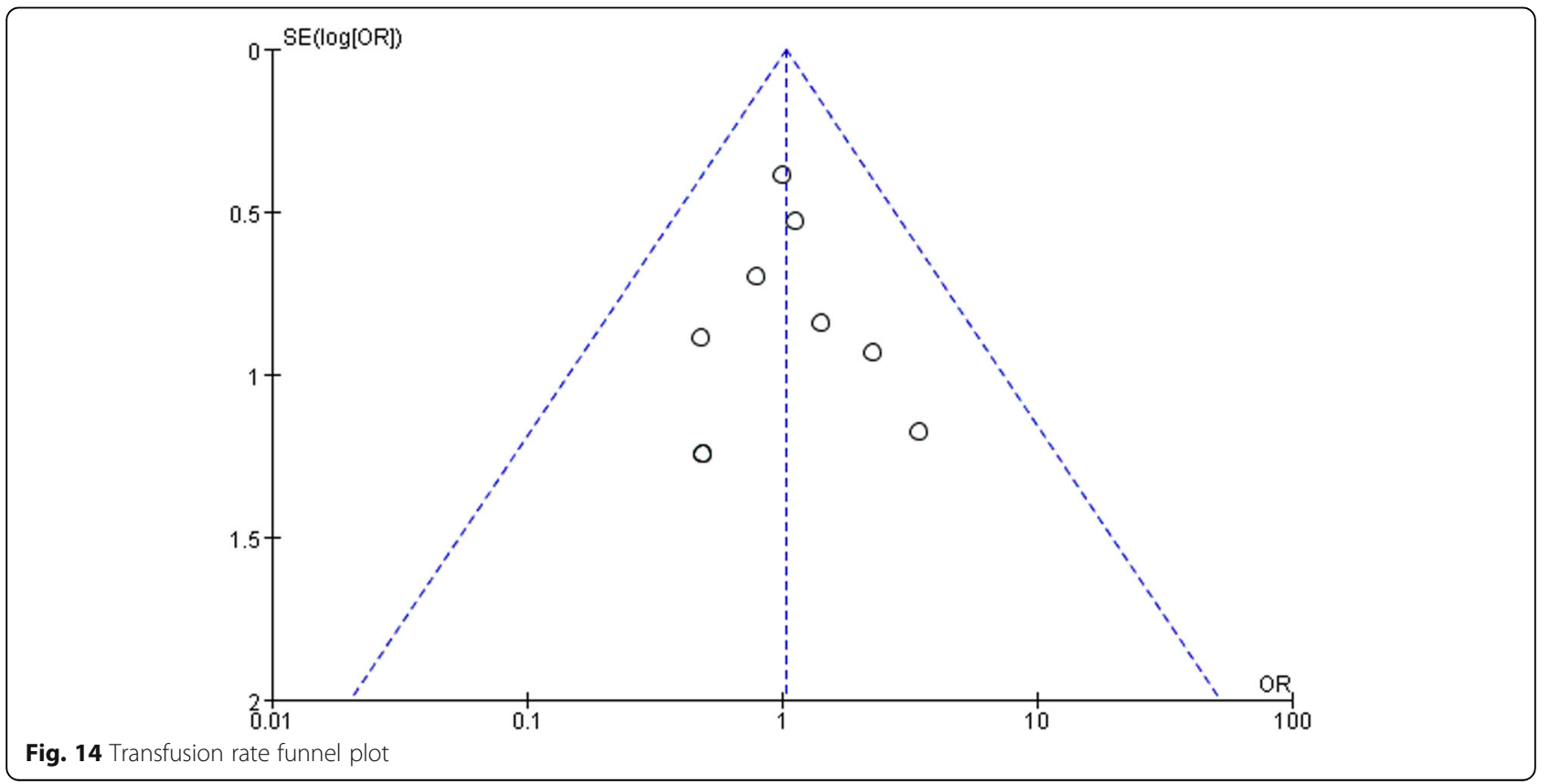




\section{Conclusion}

In conclusion, our findings suggest that compared with the intravenous use of TXA, oral application has similar clinical outcomes in terms of total blood loss, the decline in hemoglobin, the length of hospital stay, the incidence of DVT and IVT, and the transfusion rate and a lower expense.

\section{Abbreviations}

Cls: Confidence intervals; DHB: Decline of hemoglobin; DVT: Deep vein thrombosis; HS: Hospital stay; IVT: Intramuscular venous thrombosis; RRs: Relative risks; TBL: Total blood loss; TKA/THA: Total knee/hip arthroplasty; TKR/THR: Total knee/hip replacement; TXA: Tranexamic acid

\section{Acknowledgements}

There is no external assistance for the study.

\section{Authors' contributions}

All authors have contributed substantially to the conception, design, analysis, and/or interpretation of the data in this manuscript and will take public responsibility for the content. All authors read and approved the final manuscript.

\section{Funding}

This study have no funding.

\section{Availability of data and materials}

All authors consent for the availability of data and materials.

\section{Ethics approval and consent to participate}

This is a review study need not of ethics approval and consent to participate.

\section{Consent for publication}

All authors consent for publication.

\section{Competing interests}

The authors declare that they have no competing interests.

\section{Author details}

'Department of Orthopedics Medicine, Wujin People's Hospital, YongNing North Road No. 2, Changzhou 213000, Jiangsu Province, China. ${ }^{2}$ Department of Respiratory Medicine, Wujin People's Hospital, Changzhou 213000, China.

Received: 1 October 2019 Accepted: 18 December 2019

Published online: 20 January 2020

\section{References}

1. Sehat KR, Evans R, Newman JH. How much blood is really lost in total knee arthroplasty? Correct blood loss management should take hidden loss into account. Knee. 2000;7(3):151-5

2. Rosencher N, et al. Orthopedic Surgery Transfusion Hemoglobin European Overview (OSTHEO) study: blood management in elective knee and hip arthroplasty in Europe. Transfusion. 2003:43(4):459-69.

3. Cardone D, Klein AA. Perioperative blood conservation. Eur J Anaesthesiol. 2009;26(9):722-9.

4. Nadeau RP, Howard JL, Naudie DD. Antifibrinolytic therapy for perioperative blood conservation in lower-extremity primary total joint arthroplasty. JBJS Rev. 2015;3(6):1.

5. Kim TK, et al. Is lower tourniquet pressure during total knee arthroplasty effective? A prospective randomized controlled trial. BMC Musculoskelet Disord. 2019;20(1):275

6. Mannova J, et al. Evaluation of efficacy of systemic administration of tranexamic acid (Exacyl) in total hip and knee arthroplasty-prospective cohort study. Acta Chir Orthop Traumatol Cechoslov, 2019:86(2):118-23.

7. Sandri A, et al. Perioperative intravenous tranexamic acid reduces blood transfusion in primary cementless total hip arthroplasty. Acta Biomed. 2019; 90(1-S):81-6.
8. Sharqzad AS, et al. Blood loss and allogeneic transfusion for surgical treatment of periprosthetic joint infection: a comparison of one- vs. twostage exchange total hip arthroplasty. Int Orthop. 2019;43(9):2025-30.

9. Taneja A, et al. Association between allogeneic blood transfusion and wound infection after total hip or knee arthroplasty: a retrospective casecontrol study. J Bone Jt Infect. 2019:4(2):99-105.

10. Dabash $\mathrm{S}$, et al. Blood loss reduction with tranexamic acid and a bipolar sealer in direct anterior total hip arthroplasty. Am J Orthop (Belle Mead NJ). 2018;47(5):1.

11. El BH, et al. Tranexamic acid administration to older patients undergoing primary total hip arthroplasty conserves hemoglobin and reduces blood loss. Can J Surg. 2018;61(3):177-84.

12. Gianakos $A L$, et al. Reduction of blood loss by tranexamic acid following total hip and knee arthroplasty: a meta-analysis. JBJS Rev. 2018;6(5):e1

13. Sridharan K, Sivaramakrishnan G. Tranexamic acid in total hip arthroplasty: mixed treatment comparisons of randomized controlled trials and cohort studies. J Orthop. 2018;15(1):81-8.

14. Stoicea N, et al. Tranexamic acid use during total hip arthroplasty: a single center retrospective analysis. Medicine (Baltimore). 2018:97(21):e10720.

15. Yuan $X$, et al. Comparison of 3 routes of administration of tranexamic acid on primary unilateral total knee arthroplasty: a prospective, randomized, controlled study. J Arthroplast. 2017;32(9):2738-43.

16. Luo $Z Y$, et al. Oral vs intravenous vs topical tranexamic acid in primary hip arthroplasty: a prospective, randomized, double-blind, controlled study. J Arthroplast. 2018;33(3):786-93.

17. Wang D, et al. Tranexamic acid in primary total knee arthroplasty without tourniquet: a randomized, controlled trial of oral versus intravenous versus topical administration. Sci Rep. 2018;8(1):13579.

18. Fillingham YA, et al. The James A. Rand Young Investigator's Award: a randomized controlled trial of oral and intravenous tranexamic acid in total knee arthroplasty: the same efficacy at lower cost? J Arthroplast. 2016;31(9 Suppl):26-30.

19. Wu Y, et al. Blood loss and cost-effectiveness of oral vs intravenous tranexamic acid in primary total hip arthroplasty: a randomized clinical trial. Thromb Res. 2018:171:143-8.

20. Cao G, et al. Efficacy and safety of multiple boluses of oral versus intravenous tranexamic acid at reducing blood loss after primary total knee arthroplasty without a tourniquet: a prospective randomized clinical trial. Thromb Res. 2018;171:68-73.

21. Zhao H, et al. Efficacy of oral tranexamic acid on blood loss in primary total hip arthroplasty using a direct anterior approach: a prospective randomized controlled trial. Int Orthop. 2018;42(11):2535-42.

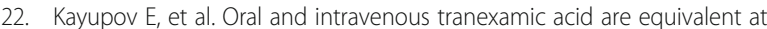
reducing blood loss following total hip arthroplasty: a randomized controlled trial. J Bone Joint Surg Am. 2017;99(5):373-8.

23. Cao G, et al. The effect of oral versus intravenous tranexamic acid in reducing blood loss after primary total hip arthroplasty: a randomized clinical trial. Thromb Res. 2018:164:48-53.

24. Zohar $\mathrm{E}$, et al. The postoperative blood-sparing efficacy of oral versus intravenous tranexamic acid after total knee replacement. Anesth Analg. 2004;99(6):1679-83. table of contents

25. Hobbs JC, et al. Epsilon aminocaproic acid to reduce blood loss and transfusion after total hip and total knee arthroplasty. J Arthroplast. 2018; 33(1):55-60.

26. Xie J, et al. Multiple boluses of intravenous tranexamic acid to reduce hidden blood loss and the inflammatory response following enhancedrecovery primary total hip arthroplasty: a randomised clinical trial. Bone Joint J. 2017:99-B(11):1442-9.

27. Newman JM, et al. Quantifying blood loss and transfusion risk after primary vs conversion total hip arthroplasty. J Arthroplast. 2017;32(6):1902-9.

28. Zan $\mathrm{P}$, et al. Efficacy of a four-hour drainage clamping technique in the reduction of blood loss following total hip arthroplasty: a prospective cohort study. Med Sci Monit. 2017:23:2708-14

29. Alipour $M$, et al. Effectiveness of oral tranexamic acid administration on blood loss after knee artroplasty: a randomized clinical trial. Transfus Apher Sci. 2013;49(3):574-7.

30. Lee QJ, Ching WY, Wong YC. Blood sparing efficacy of oral tranexamic acid in primary total knee arthroplasty: a randomized controlled trial. Knee Surg Relat Res. 2017:29(1):57-62.

31. Irwin A, et al. Oral versus intravenous tranexamic acid in enhanced-recovery primary total hip and knee replacement: results of 3000 procedures. Bone Joint J. 2013;95-B(11):1556-61. 
32. Johansson T, Pettersson LG, Lisander B. Tranexamic acid in total hip arthroplasty saves blood and money: a randomized, double-blind study in 100 patients. Acta Orthop. 2005;76(3):314-9.

33. Husted $\mathrm{H}$, et al. Tranexamic acid reduces blood loss and blood transfusions in primary total hip arthroplasty: a prospective randomized double-blind study in 40 patients. Acta Orthop Scand. 2003;74(6):665-9.

34. Gillette BP, et al. Economic impact of tranexamic acid in healthy patients undergoing primary total hip and knee arthroplasty. J Arthroplast. 2013;28(8 Suppl):137-9.

35. Wang $D$, et al. Effect of multiple doses of oral tranexamic acid on haemostasis and inflammatory reaction in total hip arthroplasty: a randomized controlled trial. Thromb Haemost. 2019;119(1):92-103.

36. Tang $Y$, et al. The efficacy and safety of multiple doses of oral tranexamic acid on blood loss, inflammatory and fibrinolysis response following total knee arthroplasty: a randomized controlled trial. Int J Surg. 2019:65:45-51.

37. Kim TK, Chang CB, Koh IJ. Practical issues for the use of tranexamic acid in total knee arthroplasty: a systematic review. Knee Surg Sports Traumatol Arthrosc. 2014;22(8):1849-58.

\section{Publisher's Note}

Springer Nature remains neutral with regard to jurisdictional claims in published maps and institutional affiliations.

Ready to submit your research? Choose BMC and benefit from:

- fast, convenient online submission

- thorough peer review by experienced researchers in your field

- rapid publication on acceptance

- support for research data, including large and complex data types

- gold Open Access which fosters wider collaboration and increased citations

- maximum visibility for your research: over $100 \mathrm{M}$ website views per year

At BMC, research is always in progress.

Learn more biomedcentral.com/submissions 